\title{
Mycorrhizal densities decline in association with nonnative plants and contribute to plant invasion
}

\author{
Keith M. Vogelsang ${ }^{1}$ and James D. Bever \\ Department of Biology, Indiana University, 1001 East Third Street, Bloomington, Indiana 47405 USA
}

\begin{abstract}
Belowground interactions between herbaceous native species and nonnative species is a poorly understood but emerging area of interest to invasive-species researchers. Positive feedback dynamics are commonly observed in many invaded systems and have been suspected in California grasslands, where native plants associate strongly with soil mutualists such as arbuscular mycorrhizal fungi. In response to disturbance, invading nonnative plants proliferate, and to the degree these species associate weakly with soil mutualists, we would expect mutualist efficacy to degrade over time. Degraded mutualist efficacy would negatively impact mutualist-dependent native species or their recruitment following a disturbance. We investigated the feedback dynamics of soil conditioned both with native and nonnative herbaceous communities of southern California grasslands to test this degraded mutualist hypothesis. Using a mesocosm approach, we inoculated each community with live soil originating from a remnant native grassland and varied the plant communities (i.e., native or nonnative) along a plant-species-richness gradient. After one year, we then used this conditioned soil for reciprocal feedback tests on a native and nonnative indicator species. We show that a native herbaceous forb (Gnaphalium californicum) grows best in soil conditioned by a diverse mix of other native species that includes $G$. californicum but is inhibited by soil conditioned by a diverse mix of nonnative species. We also show that an invasive, nonnative herbaceous forb (Carduus pycnocephalus) exhibits strong growth in soil lacking arbuscular mycorrhizal fungi and in soil conditioned by a diverse mix of nonnative species that include C. pycnocephalus, and that it is inhibited by the same soil that best promotes the native, G. californicum. Separate bioassays for mycorrhizal density show a reduction of arbuscular mycorrhizal fungi in the nonnative-conditioned soil relative to the native-conditioned soil, which suggests that nonnative species do not promote the growth of mycorrhizal fungi in the same way that native species do. The growth patterns resulting from the vegetative history of these distinct soil communities provide evidence of a biotic feedback mechanism that may account for the maintenance of persistent communities of nonnative (and often invasive) plants ubiquitous throughout California grasslands.
\end{abstract}

Key words: AMF; arbuscular mycorrhizal fungi; Carduus pycnocephalus; native; nonnative; invasive; California grasslands; feedback; Gnaphalium californicum; mutualist degradation.

\section{INTRODUCTION}

Plant-invasion dynamics have been investigated from a variety of perspectives, including a focus on plant phenology and life history characteristics (Baker 1974, 1986), species attributes (Rejmanek and Richardson 1996), and ecosystem vulnerability (Lonsdale 1999, Stohlgren et al. 2002). In systems where nonnative species become more abundant while the native vegetation declines, positive feedbacks have been implicated (Klironomos 2002, Callaway et al. 2004). For example, in the intermountain western United States, various livestock activities promoted the spread of the nonnative annual Bromus tectorum (cheatgrass; Novak and Mack 2001). With increasing cheatgrass abundance, rangeland fires have become more frequent, which generally

Manuscript received 28 December 2007; revised 6 May 2008; accepted 3 June 2008. Corresponding Editor: J. N. Klironomos.

${ }^{1}$ E-mail: kvogelsa@indiana.edu promotes cheatgrass proliferation to the detriment of the native perennials (Knapp 1996). In the absence of positive feedback, cheatgrass abundance would be expected to decline via shrub succession, but the ecological differences between cheatgrass and the native shrubs reinforces the degraded rangeland condition. In recent years, new conceptual models and empirical data suggest a role for plant-soil feedbacks, whereby plants influence their associated soil biota in ways that promote or inhibit conspecifics of subsequent generations (Bever 2003, Levine et al. 2006, Reinhart and Callaway 2006).

Soil mutualists can be agents of positive feedback, evident in Hawaiian volcanic soils, where the invasion of the evergreen tree Myrica faya and its actinorhizal mutualist alter nitrogen cycling such that the nonnative invader is self-sustained to the detriment of the native forest (Vitousek and Walker 1989, Walker and Vitousek 1991). Myrica faya can be viewed as a nonnative species with a qualitatively different relationship to soil flora 
than the displaced native species. Positive feedback between the nonnative host plant and its increasingly abundant soil mutualist has facilitated the conversion. A similar phenomenon may be occurring in the Mediterranean-type ecosystems of California, where stable communities of nonnative plants can resist native species recruitment for decades (Stromberg and Griffin 1996, Eliason and Allen 1997, Stylinski and Allen 1999). As nonnative species increase in abundance, structural changes to soil communities would become increasingly important if plant hosts varied in their ability to support rhizosphere microorganisms.

Here we hypothesize that soil mutualists in decline might also initiate positive feedback to reinforce the dominance of nonnative plants. In systems where native plants have strong mutualistic relationships with soil symbionts such as arbuscular mycorrhizal (AM) fungi, then disturbances that disrupt the mutualism could facilitate the establishment of nonnative species. If nonnative hosts are less dependent on the mutualism and invest little in maintaining microbial communities, then nonnative-dominated communities could result. These altered plant communities would appear stable if the degraded soil community prevented successful reestablishment of native species. Patterns of nonnative plant dominance could be explained by this degraded mutualist hypothesis where distinct ecologies between native and nonnative plants are suspected in the absence of clear competitive superiority.

We build this degraded mutualist hypothesis on many assumptions, each of which has empirical support. (1) Soil arbuscular mycorrhizae decline with increasing disturbance intensity, which is evident in both agricultural and unmanaged systems (Moorman and Reeves 1979, Reeves et al. 1979, Galvez et al. 2001). (2) Colonizing nonnative species are often less dependent on mutualists such as AM fungi (Reeves et al. 1979, Allen and Allen 1980, Pendleton and Smith 1983). (3) Plants vary in their AM fungal hosting ability (Newman and Reddell 1987, Trappe 1987). Testable patterns of inhibition and growth promotion emerge from this hypothesis. That is, native plants dependent on AM fungi would be inhibited when grown in killed soil or live soil with a vegetative history of nonnative species, and promoted when grown in live soil with a vegetative history of native species. The inhibition and growth promotion would be relative to the performance of nonnative plants growing under the same treatments.

In practice, however, this degraded mutualist hypothesis is difficult to test due to confounding abiotic factors inherent in most natural soils. The temporal and spatial heterogeneity of soils is well recognized, and even in the absence of differential nutrient availability, this heterogeneity can affect competitive relationships (Fransen et al. 2001). Moreover, biotic factors like soil pathogens can confound underlying predictions if soil communities feedback negatively on their host communities (Bever 1994, Mills and Bever 1998, Matthews and Clay 2001), and the effects of disturbance itself on the soil community must be considered (Moorman and Reeves 1979, Reeves et al. 1979). We controlled for these confounding soil factors in the system described here. After one year of soil conditioning using manipulated native and nonnative plant communities, we tested the feedback potential of these conditioned soils on suitable native and nonnative indicator species to learn how vegetative history influenced the soil mutualist efficacy.

\section{Methods}

\section{Experimental overview}

The experiment involved two phases. In the first phase, we constructed mesocosms that received a common soil community and were cultured with a variety of host plants for one growing season. These mesocosms were plant communities consisting entirely of native or nonnative herbaceous grassland species grown in large nursery pots. After establishing a vegetative history in each mesocosm and thus conditioning the soil, we removed soil from each pot for a growth assay to determine mycorrhizal densities and for use as inoculum in a greenhouse feedback experiment. Soil feedback effects of each conditioned soil community were tested on two taxonomically related indicator species: the native grassland forb Gnaphalium californicum and the invasive nonnative Carduus pycnocephalus. The performance of these indicator species allowed a direct test of host-community-mediated mutualist degradation.

\section{Study system}

This experiment commenced in the field over the 1999-2000 growing season at the University of California, Irving (UCI) Arboretum (Irvine, California, USA: $33^{\circ} 40^{\prime} \mathrm{N}, 117^{\circ} 51^{\prime} \mathrm{W}, 17 \mathrm{~m}$ elevation) and was completed the following year inside a university greenhouse $1.6 \mathrm{~km}$ southeast of the arboretum. The mesocosms were modeled after the low elevation coastal grasslands in Southern California. Drought conditions prevail each summer with $\sim 300 \mathrm{~mm}$ of rain occurring during the cool winter months. Winter temperatures range from $7^{\circ}$ to $19^{\circ} \mathrm{C}$ in January to $17^{\circ}$ to $28^{\circ} \mathrm{C}$ in July. The soils are generally fine textured and vary in depth; we used a local clay soil formed from weathered calcareous sandstone and shale. A diverse mix of perennial and annual grasses and forbs characterize these coastal grasslands, from which we selected common species to create two pools of grasses and forbs. The native species pool included Bloomeria crocea Torr. (common goldenstar, Liliaceae), Daucus pusillus Miscx. (yarrow, Apiaceae), Dichelostemma capitatum Benth. (blue dicks, Liliaceae), Gnaphalium californicum DC. (everlasting, Asteraceae), Isocoma menziesii Hook. \& Arn. (coast goldenbush, Asteraceae), Lotus purshianus Benth. (Spanish lotus, Fabaceae), Muhlenbergia rigens (Benth.) A. Hitchc. (deergrass, Poaceae), and Nassella pulchra A. Hitchc. (purple needlegrass, Poaceae). The 
nonnative species pool included Amaranthus retroflexus L. (pigweed, Amaranthaceae), Avena fatua L. (wild oatgrass, Poaceae), Brassica nigra (L.) Koch (black mustard, Brassicaceae), Bromus diandrus Roth (ripgut brome, Poaceae), Carduus pycnocephalus L. (Italian thistle, Asteraceae), Cirsium vulgare L. (bull thistle, Asteraceae), Melilotus indica L. (sourclover, Fabaceae), and Rumex crispus L. (curly dock, Polygonaceae). We collected soil and seed from the UCI Ecological Preserve and also from a local wildlife sanctuary owned and managed by the Audubon Society (Starr Ranch; see Plate 1).

\section{Experimental design of mesocosms}

Mesocosms consisted of either native coastal grassland species or naturalized nonnative species. Within these two assemblages (native or nonnative), we created a richness gradient of communities consisting of one, two, four, seven, or eight species. Including this gradient allowed species-number effects to be distinguished from species-composition effects. Each assemblage contained monocultures of all eight species from a given native or nonnative pool, and these monocultures were replicated four times for a total of 32 native and 32 nonnative species monocultures. In richness treatments 2 and 4, we created eight random combinations from each species pool, with the design constraint that all species must be equally represented. We replicated these eight random combinations to create 16 communities each of two and four species in each assemblage. Richness treatment 7 systematically excluded each species to form eight possible combinations, which were replicated to yield 16 communities. To keep planting density constant at eight individuals in treatment 7 , we double planted one of the species, as determined by a random draw. We used all species in richness treatment 8 , and the resulting native and nonnative communities were each replicated eight times.

We included eight containers of bare soil (designated as "no host") to estimate nutrient depletion. These bare soil pots were maintained free of weeds (and thus, potential host plants) throughout the growing season. These eight containers received the same inoculum and watering regimes as the other treatments.

\section{Mesocosm assembly}

Large plastic nursery containers $(36.8 \mathrm{~cm}$ diameter $\times$ $38.1 \mathrm{~cm}$ height; $40 \mathrm{~L}$ capacity) were used to house communities of plants and their common soil inoculum. These 184 pots were evenly distributed over a $200-\mathrm{m}^{2}$ area nested within a $400-\mathrm{m}^{2}$ fenced enclosure. A nylon fabric barrier underneath the array limited weed proliferation in the interspaces. Each of the 184 pots was filled to $75 \%$ capacity with a $1: 1$ homogeneous mixture of washed sand and local soil that had been processed through a $1.3-\mathrm{cm}$ sieve. To remove weeds, the pots of soil were regularly watered for eight weeks to induce seed bank germination and these weeds were promptly removed by hand. This management regime likely reduced the viability of obligate soil mutualists such as AM fungi. To reestablish these soil communities and incorporate species associated with native coastal grasslands, we added $225 \mathrm{~mL}$ of live soil to inoculate each pot. This live soil inoculum was then capped by a 4 $\mathrm{cm}$ layer of homogenized soil that had been autoclaved for three hours at $121^{\circ} \mathrm{C}$.

Each mesocosm received eight seedlings that were grown in a UCI greenhouse for several weeks in a sterile mix of vermiculite and peat moss. We used a radially symmetrical planting pattern to keep seedlings evenly spaced. The area received $159 \mathrm{~mm}$ of rainfall over the growing season, which was well below the annual mean precipitation of $312 \mathrm{~mm}$. Thus, pots were hand-watered uniformly to supplement rain inputs. A species inventory conducted post-establishment (after 8 weeks) determined surviving density and species richness for each mesocosm so that these factors could be accounted for in all subsequent analyses.

\section{Soil inoculum preparation}

Live soil obtained from an undisturbed area of Starr Ranch in February 1999 was selected to represent the soil biota of a native perennial coastal grassland. Approximately $500 \mathrm{~mL}$ of this soil was used as a starter inoculum grown with a diverse mix of California grassland host species, and cultured in 12-L nursery pots as a way to increase the total volume of potential inoculum. Live soil collected from Starr Ranch in October 1999 was used to augment the cultured inoculum. Both the cultured and the live soil contained root fragments, fungal hyphae, and other microorganisms ubiquitous in native soils. A separate infectionpotential assay indicated that sufficient live propagules were present in this prepared inoculum (mean root colonization on grain sorghum $>50 \%$ ). Each mesocosm received $150 \mathrm{~mL}$ of cultured soil inoculum and $75 \mathrm{~mL}$ of live fresh soil inoculum as indicated previously.

\section{Mesocosm harvest}

All above-ground plant material was harvested at the end of the growing season, sorted to species and then oven dried at $65^{\circ} \mathrm{C}$ to a constant mass for weighing. Both community types exhibited $100 \%$ vegetative cover. On a biomass basis, the nonnative communities outperformed the slower growing native communities by a wide margin (nonnative $=224.4 \pm 14.1 \mathrm{~g}$, native $=62.1$ $\pm 4.0 \mathrm{~g}[$ mean $\pm \mathrm{SE}])$.

\section{Test of soil nutrient content}

To test the feedback potential of the soil communities cultured under the mesocosm host plants, we removed soil samples from the center of each pot. These soil samples were removed following the 1999-2000 growing season after completion of the plant harvest. Since these soils would later be used as inoculum, it was important to test for differences in macronutrients that may 
influence growth responses. Each sample was air dried and subsampled to determine available nitrate $\left(\mathrm{NO}_{3}{ }^{-}\right)$, ammonium $\left(\mathrm{NH}_{4}^{+}\right)$, Olsen extractable phosphorus $(\mathrm{P})$, and potassium $(\mathrm{K})$ by an independent laboratory (DANR Analytical Laboratories, University of California, Davis, Davis, California, USA). We refrigerated the remaining soil until February 2001, at which time subsamples were removed for use as post-mesocosm inoculum.

\section{Mycorrhizal infection potential assay}

Investigating mutualist viability required an independent assay of mycorrhizal density on a general-purpose host. The ubiquity and ecological importance of AM fungi make this group of obligate mutualists good candidates for any feedback effects initiated by manipulated host communities. In a manner similar to the test for soil feedback, a set of 184 small seedling cones (3.8 $\mathrm{cm}$ diameter $\times 21 \mathrm{~cm}$ depth; Stuewe and Sons, Corvallis, Oregon, USA) were filled with autoclaved local soil and sand mixed 1:1 (volume: volume) previously sieved to exclude aggregates $>4.75 \mathrm{~mm}$. Each cone received 10 $\mathrm{mL}$ of post mesocosm inoculum combined with $90 \mathrm{~mL}$ of the autoclaved planting mix. An additional set of eight cones received only $100 \mathrm{~mL}$ of autoclaved mix and no live inoculum. All cones were seeded with grain sorghum, completely randomized in a UCI greenhouse, and watered daily. After two weeks, all plants received $10 \mathrm{~mL}$ phosphorus-free fertilizer diluted to $300 \mathrm{ppm}$ nitrate (Plant Marvel Laboratories, Chicago Heights, Illinois, USA). All plants were harvested at 24 days, and the roots were washed, cleared with $10 \% \mathrm{KOH}$, and stained with trypan blue. The stained roots were randomly subsampled and mounted onto glass slides for inspection under a light microscope. We estimated the mycorrhizal colonization percentage of each sample visually according to methods adapted from McGonigle et al. (1990).

\section{Test of soil feedback}

We investigated the feedback potential of soil used in the previous year's mesocosm on two indicator species: the native grassland forb Gnaphalium californicum and the nonnative forb Carduus pycnocephalus (for both species, we use the genus name only from this point forward). These species grow abundantly throughout coastal sage/scrub and coastal grassland communities, and they grew reliably in their respective native and nonnative mesocosms. These plants both exhibit similar morphologies and biennial life histories, and are known to form mycorrhizae (i.e., they are mycotrophic). Since mycotrophy is common in Mediterranean-type ecosystems characterized by nutrient-poor soils, both of these species were likely to be good indicators for mutualist effects.

For precision volume measurements, we crushed post mesocosm inoculum through a sterilized $2 \mathrm{~mm}$ sieve to obtain $50 \mathrm{~mL}$ of inoculum which was then mixed with
$150 \mathrm{~mL}$ of autoclaved soil and sand, mixed 1:1 (volume: volume). We placed these mixtures into two sets of 184 seedling cones $(5 \mathrm{~cm}$ diameter $\times 18 \mathrm{~cm}$ depth). Each set of 184 cones corresponded directly to the treatments from the previous year's mesocosm system, thus preserving the original replication. Two sets of five cones filled only with $200 \mathrm{~mL}$ of autoclaved soil were added as sterile controls. Seeds of Gnaphalium and Carduus were randomly assigned to one of the sets, and each set completely randomized across the greenhouse bench. These seeds were covered with $10 \mathrm{~mL}$ of autoclaved soil:sand mix, and all cones were gently misted daily to induce germination. Seedlings were thinned to one individual per cone post emergence, and allowed to grow for 12 weeks in a UCI greenhouse under natural light conditions. Since this experiment investigated mutualist viability, we maintained low phosphorus growing conditions to facilitate root-AM fungal interactions. Thus in addition to daily watering, all cones received $10 \mathrm{~mL}$ of phosphorus-free watersoluble fertilizer diluted to $300 \mathrm{ppm}$ nitrate. This solution was applied four times $(40 \mathrm{~mL}$ total) approximately every fourth week, which corresponded to symptoms of nitrogen deficiency exhibited by the plants. Moreover, any nutrient availability introduced by the inoculum itself was likely mitigated by this fertilization regime. During this time, both completely randomized arrays were rotated every 10 days to mitigate any block effects due to greenhouse bench position. The roots and shoots of all plants were harvested after 12 weeks, oven dried at $65^{\circ} \mathrm{C}$ to a constant mass, and weighed.

\section{Data analysis}

Soil nutrient differences of the post mesocosm inocula were evaluated for differences by vegetative status (vegetated or bare) and mesocosm type (native or nonnative). The minerals $\mathrm{NO}_{3}{ }^{-}, \mathrm{NH}_{4}{ }^{+}, \mathrm{P}$, and $\mathrm{K}$ were included as multiple responses in a MANOVA that used community type as the independent class variable. Orthogonal contrasts determined whether the bare-soil nutrient controls differed from all vegetated treatments, and also whether nutrients differed among native and nonnative communities.

The mycorrhizal colonization data were first analyzed to detect overall differences among the five postmesocosm inoculum types of (1) sterile controls, (2) no host plants, (3) nonnative hosts only, and (4) native hosts only. Estimates of the percentage of mycorrhizal colonization of sorghum roots were analyzed using ANOVA. Unequal means were evaluated with the post hoc Tukey procedure, and we contrasted native and nonnative host soil communities using a planned comparison. A restricted ANCOVA then considered only the effects of manipulated host-community richness and host origin, with soil mineral estimates from the mesocosm inoculum as covariates. Backward elimination removed nonsignificant $(P>0.05)$ covariates from the final model. 
TABLE 1. Mean soil nutrient levels $(\mathrm{mg} / \mathrm{kg} ; \pm \mathrm{SE})$ from soil conditioned in mesocosms after one season.

\begin{tabular}{lccccc}
\hline \hline $\begin{array}{c}\text { Host-community } \\
\text { type }\end{array}$ & $\begin{array}{c}\text { No. mesocosm } \\
\text { containers }\end{array}$ & Ammonium & Nitrate & Phosphorus & Potassium \\
\hline No host & 8 & $2.9 \pm 0.59$ & $27.1 \pm 2.81$ & $7.0 \pm 0.69$ & $130 \pm 17.2$ \\
Nonnative & 88 & $3.1 \pm 0.12$ & $2.9 \pm 0.40$ & $3.9 \pm 0.16$ & $134 \pm 5.1$ \\
Native & 80 & $2.9 \pm 0.07$ & $1.4 \pm 0.27$ & $3.6 \pm 0.16$ & $119 \pm 3.5$ \\
\hline
\end{tabular}

Note: This soil was used to inoculate a mycorrhizal colonization assay and a feedback assay on a native and a nonnative indicator species.

Data (total dry biomass) from the greenhouse growth assay of Gnaphalium and Carduus were first analyzed to detect overall differences among the same five inoculum types used for the mycorrhizal colonization assay. Individual plants failing to germinate or survive more than three weeks were excluded; germination for Gnaphalium was low compared to Carduus, which resulted in 35\% fewer observations for Gnaphalium. Additionally, eight inoculum samples of the original 184 mesocosms were excluded from all analyses because the soil communities originated from "dead" mesocosms, i.e., where seedlings were planted but died early in the growing season. Biomass data for both species were natural-log transformed $(\ln (1+Y))$ to satisfy variance assumptions. The unequal sample sizes in both data sets coupled with the heteroscedasticity necessitated nonparametric procedures, and so the four groups were compared using the Kruskal-Wallis test.

Separate analyses focused only on the effects of manipulated host-community richness and host origin. For these analyses, pots lacking host communities were excluded. This restricted data set exhibits good homoscedasticity, allowing parametric procedures. Thus, twoway analyses of covariance on the growth of Gnaphalium and Carduus used community type (native or nonnative) and species richness as main effects, and the results from the mineral analyses on the source inoculum as covariates. Since richness varied independently in the mesocosm, including species richness in this manner tests for any species number effects that are separate from species composition effects. We used backward elimination to systematically exclude nonsignificant soil nutrients from the final model, using $P>0.05$ as the exclusion rule. For both species, the final model included the main effects of community type and species richness, along with the interaction term community type $x$ richness with no significant soil nutrients as covariates. All analyses were performed using SAS version 9 (SAS 2003).

\section{Results}

\section{Test of soil nutrient content}

The three community types exhibited significant differences in extractable soil minerals (MANOVA $\left.F_{8,340}=38.46, P<0.0001\right)$. The minerals $\mathrm{NO}_{3}{ }^{-}$and $\mathrm{P}$ influenced the overall result, with contrasts revealing significantly higher levels of $\mathrm{NO}_{3}{ }^{-}$and $\mathrm{P}$ in the bare-soil controls than in the vegetated communities $\mathrm{NO}_{3}^{-}$, $F_{1,173}=386.21, P<0.0001 ;$ phosphorous, $F_{1,173}=$ $39.14, P=0.0001$ ). The minerals $\mathrm{NH}_{4}{ }^{+}$and $\mathrm{K}$ did not differ from the controls. The contrast between native and nonnative host communities revealed significantly higher levels of $\mathrm{NO}_{3}{ }^{-}$in nonnative mesocosms $\left(F_{1,173}=\right.$ $8.32, P<0.01)$ along with elevated levels of $\mathrm{K}\left(F_{1,173}=\right.$ $6.01, P=0.02)$. No other mineral differences were evident (Table 1).

\section{Mycorrhizal infection potential assay}

Mean colonization differences ranged from $7.1 \%$ (for the sterile controls) to $56.3 \%$ for the native host-soil community, which exhibited the highest potential for mycorrhizal colonization (Fig. 1). The overall effects of inoculum source differed significantly $\left(F_{3,180}=20.74, P\right.$ $<0.0001$ ), with most colonization occurring in the three live-soil treatments. A post hoc analysis revealed the native and nonnative treatments were significantly higher than the sterile assay controls, but roots from these assay controls were not significantly more colonized than roots inoculated with soil from pots lacking host plants. The orthogonal contrast between the native and nonnative soil communities detected significant differences $\left(F_{1,180}=20.22, P<0.0001\right)$, suggesting increased density of arbuscular mycorrhizal (AM) fungi in native host soil community relative to the nonnative host soil community. ANCOVA on the restricted data set (comprised only of native and nonnative postmesocosm inoculum) indicated no overall host-species richness effects but significant host-community effects $\left(F_{1,98}=3.88, P=0.05\right)$. The ANCOVA further revealed significant species origin effects (Fig. $2 ; F_{1,155}=15.38, P$ $<0.0001$ ), no colonization effects due to host-species richness, and no response to richness within native and nonnative host soil communities. None of the mineral covariates were significant predictors and were thus dropped from the final model.

\section{Test of soil feedback for native indicator}

The most vigorous plants for the native Gnaphalium grew with inoculum from native host communities, and to a lesser extent, the inoculum from nonnative host communities (Fig. 3). Of these vigorous plants, the orthogonal contrast between the native and nonnative host soil communities $\left(F_{1,98}=3.88, P=0.05\right)$ is of particular interest because it suggests that an important 


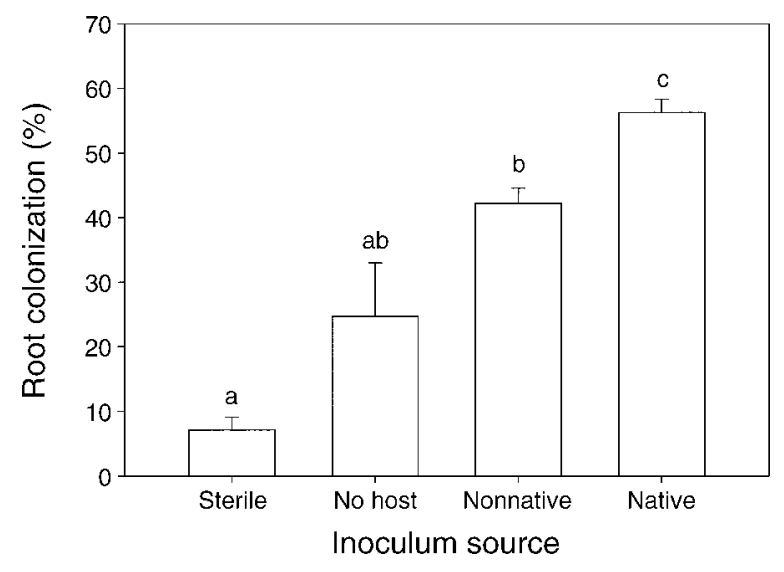

FIG. 1. The mycorrhizal colonization percentage on sorghum grown with soil conditioned for one season in a mesocosm experiment (means $+\mathrm{SE}$, with shared letters indicating nonsignificant differences). Differences in mycorrhizal density by community type are evident, with native mesocosms harboring the greatest potential as a source of mycorrhizal inoculum. Post hoc comparisons revealed no significant differences between soil from pots lacking host plants and nonnative treatments. The overall pattern suggests that community type can affect mutualist efficacy.

shift occurred in mutualist efficacy due to the nonnative hosts, and this shift resulted in a $30 \%$ loss of productivity. We find no significant soil mineral effects or interaction of host-community origin and species richness (Fig. 4a). Strong overall growth differences (using the complete data set) were significant (KruskalWallis ANOVA, $\chi_{3}^{2}=23.86, P<0.0001$ ) and were most noticeable in the sterile controls and when Gnaphalium grew with inoculum cultured without host plants. This native plant failed to thrive in either of these two treatment groups (Fig. 3a).

\section{Test of soil feedback for nonnative indicator}

The nonnative indicator Carduus was inhibited most by soil from the native host communities, and mean biomass was nearly $14 \%$ greater in the nonnative inoculum compared to the native treatment. The orthogonal contrast between the native and nonnative host soil communities differs significantly $\left(F_{1,155}=8.30\right.$, $P=0.005)$. ANCOVA on the native and nonnative host soil communities (the restricted data set) revealed significant host-species richness effects $\left(F_{6,155}=2.14, P\right.$ $=0.05$ ) and host-community effects (Fig. 4b), with Carduus being most inhibited by soil from the native host communities $\left(F_{1,155}=8.30, P=0.005\right)$. Available soil minerals were not significant biomass predictors. The nonnative indicator grew well throughout the experiment, but analysis on the complete data set reveals significant differences among the five inoculum types (Kruskal-Wallis ANOVA, $\chi_{3}^{2}=22.40, P<0.0001$ ). Carduus performed best when grown with sterile soil and inoculum cultured without host plants, in sharp contrast to the native Gnaphalium. The overall pattern of growth differs noticeably between the native and nonnative indicator species (Fig. 3).

\section{Discussion}

Several authors have observed that the large areas of California dominated by nonnative plants appear to be resistant to reinvasion by native plant species (Stromberg and Griffin 1996, Eliason and Allen 1997, Stylinski and Allen 1999), but the mechanism for this stability has not been identified. We find evidence that the reduction in mycorrhizal density by the nonnatives can inhibit the success of Gnaphalium, our native indicator species. Communities of nonnative plants are poorer hosts for mycorrhizal fungi than the communities of native plants. Moreover, our native indicator species was strongly responsive to live-soil communities and grew particularly well with soil previously conditioned by native plant species. Conversely, Carduus, our nonnative indicator species, grew better in sterile soil than with live-soil communities and grew poorly with soil previously conditioned with native plant species. With natives doing better in soil communities conditioned by native plant species and nonnatives growing better on soil communities conditioned by nonnative plant species, we have confirmed a positive feedback dynamic that can reinforce the initial dominance of nonnative plants.

This experiment provides strong support that arbuscular mycorrhizal fungi are a major component of this positive feedback dynamic, but the significant differences in inoculum mineral levels allows for the possibility of abiotic rather than biotic growth responses. However, we minimized the influence of these abiotic differences by using a small volume of inoculum within a much larger volume of homogenous sterile soil, and further reduced any nutrient effects with supplemental fertilizer. Moreover, all mineral predictors lacked significance in the analysis, thus not supporting these particular abiotic

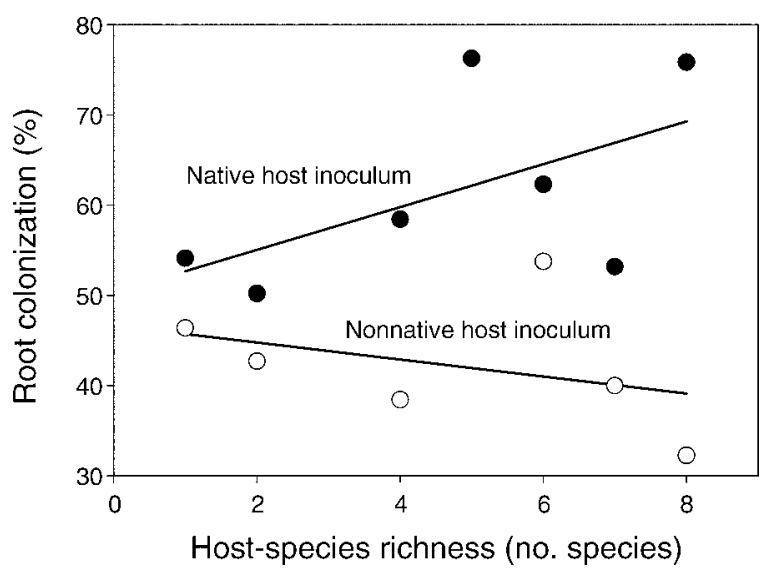

FIG. 2. The mycorrhizal colonization percentage on sorghum by host-species richness for native and nonnative inocula. The significant origin effects suggest that native and nonnative plant communities differ in their relationship to arbuscular mycorrhizal fungi. 


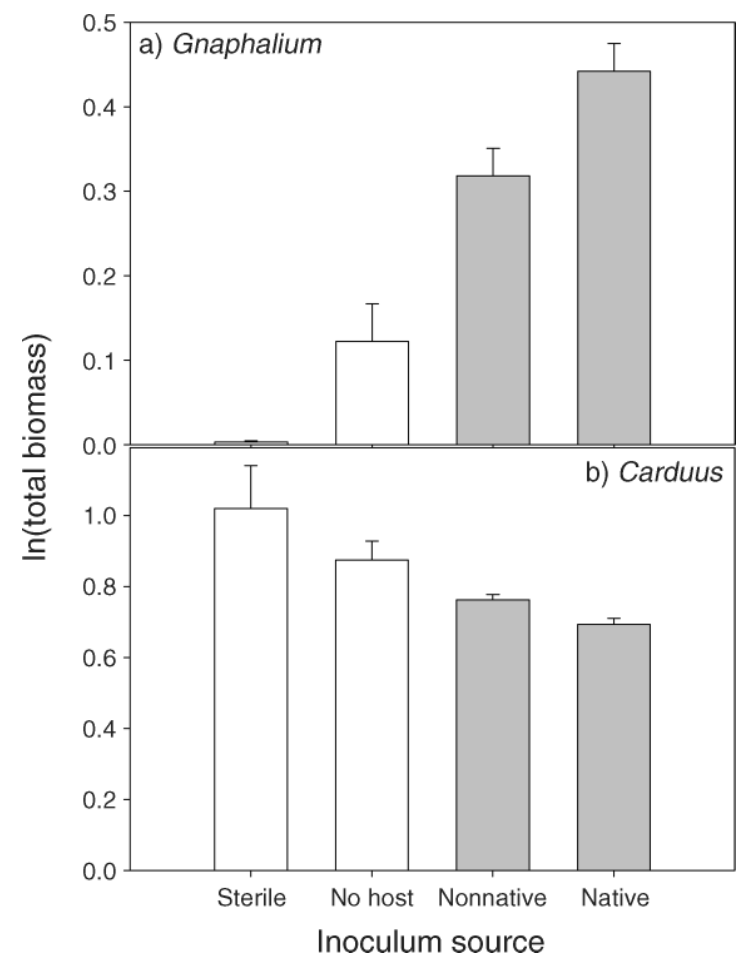

FIG. 3. A test of conditioned soil on the growth of (a) a native forb, Gnaphalium californicum, and (b) a nonnative thistle, Carduus pycnocephalus (means $+\mathrm{SE}$ ). The soil conditioning effects of native and nonnative host communities (shaded bars) were highly significant for both indicator species. Overall differences (all bars) were evaluated nonparametrically to account for the unequal variances (see Results: Test of soil feedback for native indicator and Results: Test of soil feedback for nonnative indicator). Observations for sterile treatment on Gnaphalium were three orders of magnitude smaller than the other treatments. The vertical scales differ between panels to illustrate the response pattern rather than the differential growth rates. Sample size varies by treatment and indicator species due to experimental design and differential survival. For Gnaphalium (left to right), $n=5,3,58$, and 53 mesocosm containers; for Carduus, $n=5,8,88$, and 80 mesocosm containers.

influences. The sharp reduction in mycorrhizal density we observed in the nonnative communities (Fig. 1) may be sufficient to explain the positive feedback observed here. Effects from other soil biota cannot be ruled out in the Gnaphalium and Carduus assays, but the results from the three assays considered together argue for the more parsimonious mycorrhizal mechanism.

Distinct ecologies between these particular native and nonnative species are revealed in part by the significant species richness effects, which occurred as a main effect on Carduus (Fig. 4b). Intriguingly, these species-richness effects were not observed in the Gnaphalium assay (Fig. 4a), where they might be expected from the trends observed in the mycorrhizal colonization assay (Fig. 2). Although these mycorrhizal density trends were not significant as a richness by host-community origin interaction, the significant main effects of species origin are nonetheless striking in the context of distinct ecologies between the suite of species in these native and nonnative communities. In native communities, increasing species richness creates a greater likelihood of including a preferred host, whereas in nonnative communities, increasing species richness creates a greater likelihood of including unsuitable mycorrhizal hosts. Gnaphalium growth declined at intermediate levels of host-species richness only to increase again with the highest richness treatments, resulting in no overall significant richness by host-community-origin interaction. Carduus was clearly inhibited as the number of host species increased. We interpret this as evidence that native and nonnative species can interact differently with common mutualists.

The ecological differences between Gnaphalium and Carduus may be due in part to growth trade-offs. The nonnative Carduus grows faster than the native Gnaphalium (Fig. 3). The facultative habit of this nonnative species may trade off rapid growth for decreased mycorrhizal investment. This trade-off may become especially beneficial to the slower growing Gnaphalium, which exhibits an obligate relationship to its arbuscular mycorrhizal AM fungi (Fig. 3). The increased mycorrhizal investment by the native not only improves its access to nutrients, but in the presence of effective

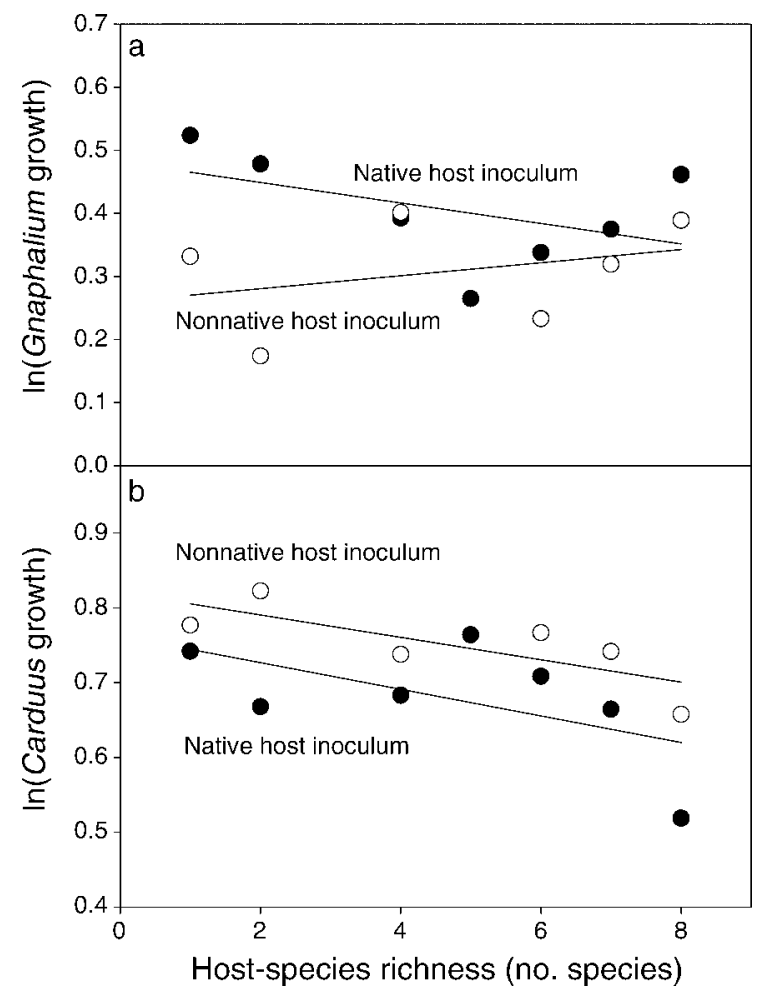

FIG. 4. The productivity of (a) a native forb, Gnaphalium californicum, and (b) the nonnative thistle Carduus pycnocephalus when grown in soil conditioned by native (solid circles) and nonnative (open circles) host communities over a species richness gradient. 


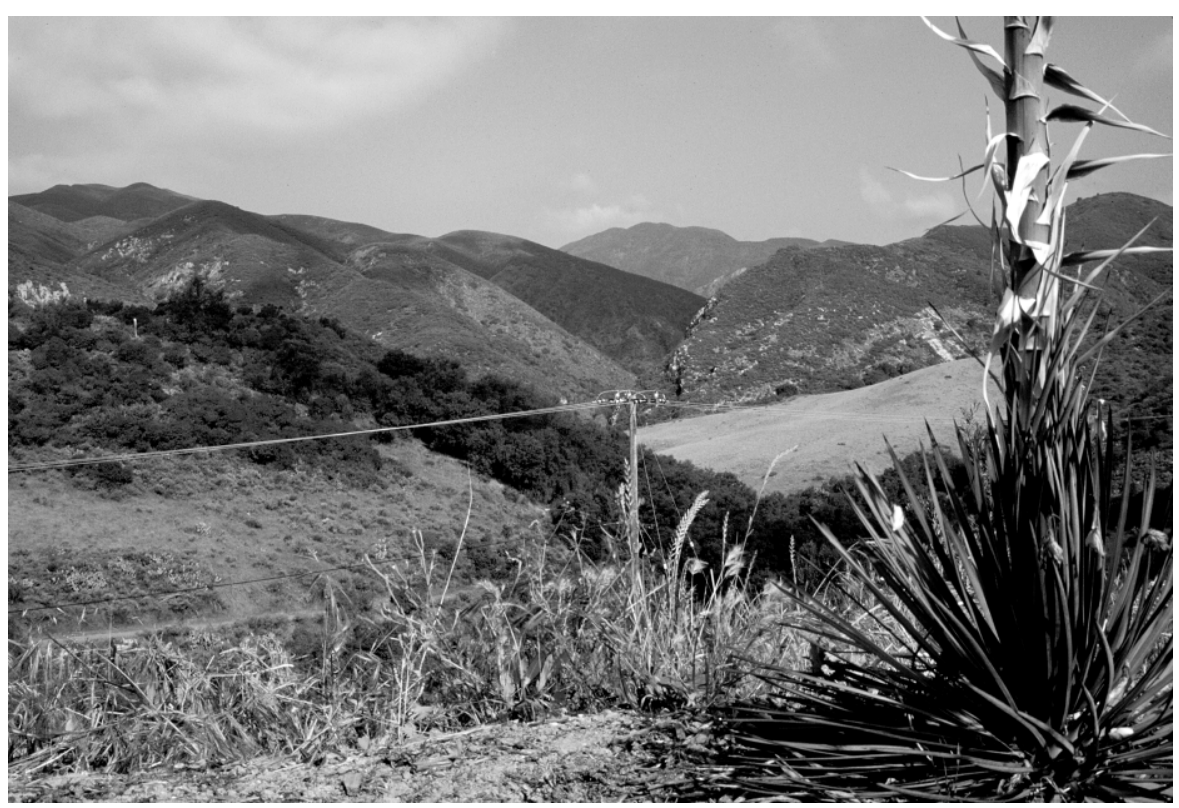

Plate 1. Overlook from the northern boundary of Starr Ranch Sanctuary, a 4000-acre preserve in Orange County, California, USA. The National Audubon Society owns and manages the property. Photo credit: K. M. Vogelsang.

mycorrhizal mutualists, may also inhibit the success of competing species exhibiting less dependence. Janos (1980) has theorized that in nutrient-poor soils capable of supporting mycorrhizae, obligate mycotrophs should dominate. Data reported here are consistent with the mycorhizal dependence of the dynamics underlying Janos's prediction.

This study demonstrates how positive feedback between plants and their soil mutualists can reinforce the initial dominance of nonnative plant species. The plant community can alter the density of the soil community, and this altered soil community can influence host performance. In natural communities characterized by high mycorrhizal dependency, such as the Mediterranean-type ecosystems of California, disturbance of the soil community can give an advantage to nonnative species that are less dependent on mycorrhizae. These nonnatives then contribute less to maintenance of the AM fungal community which can facilitate additional nonnative invasions while also limiting reestablishment of native plant species. We see evidence of this mechanism in restoration attempts where the survival probability of a native bunchgrass (Nassella pulchra) declines with increasing productivity of the nonnative site condition, even with the removal of competing annual grasses (Lombardo et al. 2007). Stinson et al. (2006) discovered a similar phenomenon in a temperate forest system where garlic mustard, an invasive herb, reduced the density of mycorrhizal fungi to the detriment of native woody species highly dependent on the mycorrhizal mutualism. It is therefore possible that these dynamics promote nonnative plant dominance to produce long-term patterns of stability, or otherwise alter plant community composition. Other mechanisms may also be important. For example, nonnative grasses are known to limit native performance by competing for soil water (Eliason and Allen 1997). This suggests native plant communities in Mediterranean-type ecosystems are prone to multiple mechanisms that negatively impact native community structure. Indeed, these mechanisms may interact, but additional work is necessary to investigate this possibility.

\section{ACKNOWLEDGMENTS}

This work was supported by awards from the Land Institute and the California Native Plant Society to K. M. Vogelsang and by the California Department of Transportation to J. D. Bever and K. M. Vogelsang. We are grateful for support and encouragement from S. DeSimone at Starr Ranch Wildlife Sanctuary, P. Bowler at the UC Natural Reserve System, and F. Carpenter at UCI. Technical assistance was provided by S. Bahreinifar, F. Becerra, A. Chahbouni, J. Ching, P. Joe, J. Kang, D. Kong, H. Nguyen, A. Sadatrafiei, and J. Walsh. We extend our sincere thanks for this essential help. Comments by $\mathrm{K}$. Howe greatly improved an early version of this manuscript, and we thank our anonymous reviewers for their comments and insight.

\section{Literature Cited}

Allen, E. B., and M. F. Allen. 1980. Natural re-establishment of vesicular arbuscular mycorrhizae following stripmine reclamation in Wyoming. Journal of Applied Ecology 17:139-147.

Baker, H. G. 1974. The evolution of weeds. Annual Review of Ecology and Systematics 5:1-24.

Baker, H. G. 1986. Patterns of plant invasions in North America. Pages 44-57 in H. A. Mooney and J. A. Drake, editors. Ecology of biological invasions of North America and Hawaii. Springer-Verlag, New York, New York, USA.

Bever, J. D. 1994. Feedback between plants and their soil communities in an old field community. Ecology 75:19651977. 
Bever, J. D. 2003. Soil community feedback and the coexistence of competitors: conceptual frameworks and empirical tests. New Phytologist 157:465-473.

Callaway, R. M., G. C. Thelen, S. Barth, P. W. Ramsey, and J. E. Gannon. 2004. Soil fungi alter interactions between the invader Centaurea maculosa and North American natives. Ecology 85:1062-1071.

Eliason, S. A., and E. B. Allen. 1997. Exotic grass competition in suppressing native shrubland re-establishment. Restoration Ecology 5:245-255.

Fransen, B., H. de Kroon, and F. Berendse. 2001. Soil nutrient heterogeneity alters competition between two perennial grass species. Ecology 82:2534-2546.

Galvez, L., D. D. Douds, L. E. Drinkwater, and P. Wagoner. 2001. Effect of tillage and farming system upon VAM fungus populations and mycorrhizas and nutrient uptake of maize. Plant and Soil 228:299-308.

Janos, D. P. 1980. Mycorrhizae influence tropical succession. Biotropica 12:56-64.

Klironomos, J. N. 2002. Feedback with soil biota contributes to plant rarity and invasiveness in communities. Nature 417:6770.

Knapp, P. A. 1996. Cheatgrass (Bromus tectorum L.) dominance in the Great Basin Desert: history, persistence, and influences to human activities. Global Environmental Change-Human and Policy Dimensions 6:37-52.

Levine, J. M., E. Pachepsky, B. E. Kendall, S. G. Yelenik, and J. H. R. Lambers. 2006. Plant-soil feedbacks and invasive spread. Ecology Letters 9:1005-1014.

Lombardo, K., J. S. Fehmi, K. J. Rice, and E. A. Laca. 2007. Nassella pulchra survival and water relations depend more on site productivity than on small-scale disturbance. Restoration Ecology 15:177-178.

Lonsdale, W. M. 1999. Global patterns of plant invasions and the concept of invasibility. Ecology 80:1522-1536.

Matthews, J. W., and K. Clay. 2001. Influence of fungal endophyte infection on plant-soil feedback and community interactions. Ecology 82:500-509.

McGonigle, T. P., M. H. Miller, D. G. Evans, G. L. Fairchild, and J. A. Swan. 1990. A new method which gives an objective measure of colonization of roots by vesicular arbuscular mycorrhizal fungi. New Phytologist 115:495-501.

Mills, K. E., and J. D. Bever. 1998. Maintenance of diversity within plant communities: soil pathogens as agents of negative feedback. Ecology 79:1595-1601.

Moorman, T., and F. B. Reeves. 1979. The role of endomycorrhizae in revegetation practices in the semi-arid west: II. A bioassay to determine the effect of land disturbance on endomycorrhizal populations. American Journal of Botany 66:14-18.
Newman, E. I., and P. Reddell. 1987. The distribution of mycorrhizas among families of vascular plants. New Phytologist 106:745-751.

Novak, S. J., and R. N. Mack. 2001. Tracing plant introduction and spread: genetic evidence from Bromus tectorum (cheatgrass). BioScience 51:114-122.

Pendleton, R. L., and B. N. Smith. 1983. Vesicular-arbuscular mycorrhizae of weedy and colonizer plant species at disturbed sites in Utah. Oecologia 59:296-301.

Reeves, F. B., D. Wagner, T. Moorman, and J. Kiel. 1979. The role of endomycorrhizae in revegetation practices in the semiarid west. I. A comparison of incidence of mycorrhizae in severely disturbed vs. natural environments. American Journal of Botany 66:6-13.

Reinhart, K. O., and R. M. Callaway. 2006. Soil biota and invasive plants. New Phytologist 170:445-457.

Rejmanek, M., and D. M. Richardson. 1996. What attributes make some plant species more invasive? Ecology 77:16551661.

SAS. 2003. SAS/STAT Version 9. SAS Institute, Cary, North Carolina, USA.

Stinson, K. A., S. A. Campbell, J. R. Powell, B. E. Wolfe, R. M. Callaway, G. C. Thelen, S. G. Hallett, D. Prati, and J. N. Klironomos. 2006. Invasive plant suppresses the growth of native tree seedlings by disrupting belowground mutualisms. PLoS Biology 4:727-731.

Stohlgren, T. J., G. W. Chong, L. D. Schell, K. A. Rimar, Y. Otsuki, M. Lee, M. A. Kalkhan, and C. A. Villa. 2002. Assessing vulnerability to invasion by nonnative plant species at multiple spatial scales. Environmental Management 29: 566-577.

Stromberg, M. R., and J. R. Griffin. 1996. Long-term patterns in coastal California grasslands in relation to cultivation, gophers, and grazing. Ecological Applications 6:1189-1211.

Stylinski, C. D., and E. B. Allen. 1999. Lack of native species recovery following severe exotic disturbance in southern Californian shrublands. Journal of Applied Ecology 36:544554.

Trappe, J. M. 1987. Phylogenetic and ecologic aspects of mycotrophy in the angiosperms from an evolutionary standpoint. Pages 5-25 in G. R. Safir, editor. Ecophysiology of VA mycorrhizal plants. CRC Press, Boca Raton, Florida, USA.

Vitousek, P. M., and L. R. Walker. 1989. Biological invasion by Myrica faya in Hawai'i: plant demography, nitrogen fixation, ecosystem effects. Ecological Monographs 59:247-265.

Walker, L. R., and P. M. Vitousek. 1991. An invader alters germination and growth of a native dominant tree in Hawaii. Ecology 72:1449-1455. 